\title{
Characteristic Qualities Impacting Landed House Prices: Better homes, better livelihood
}

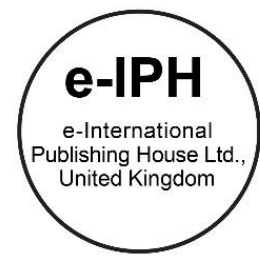

\author{
Muhamad Hilmi Mohamad @ Masri ${ }^{\star 1}$, Abdul Hadi Nawawi ${ }^{1}$, \\ Edie Ezwan Mohd Safian², Ahmad Fawwaz Ahmad Saleh ${ }^{1}$
}

${ }^{1}$ Department of Postgraduate Studies, Faculty of Architecture, Planning and Surveying, Universiti Teknologi MARA (UiTM), 40450 Shah Alam, Selangor, Malaysia 2Universiti Tun Hussein Onn Malaysia, 86400 Batu Pahat, Johor, Malaysia

\begin{abstract}
The research was conducted to find the characteristics quality of houses in Malaysia. The aim of this research was to produce the ranking characteristics of house qualities, and determining its weightages. The methodology used in this research was primarily by using the Delphi Method to ascertain characteristics quality and also Analytical Hierarchy Process to determine the ranking of the characteristics quality. Data collection gathered through a structured questionnaire that incorporates the element of Saaty's Scale using variables outlined from review and interview. A theoretical framework of the research was established from this that will lead to future research model.

Keywords: House Quality; House Price; AHP; Delphi

ISSN: 2398-4287@ 2017. The Authors. Published for AMER ABRA by e-International Publishing House, Ltd., UK. This is an open access article under the CC BYNC-ND license (http://creativecommons.org/licenses/by-nc-nd/4.0/). Peer-review under responsibility of AMER (Association of Malaysian Environment-Behaviour Researchers), ABRA (Association of Behavioural Researchers on Asians) and CE-Bs (Centre for Environment-Behaviour Studies), Faculty of Architecture, Planning \& Surveying,
\end{abstract} Universiti Teknologi MARA, Malaysia.

\section{Introduction}

The characteristics quality of houses are significant to find out especially in Malaysia, and how this can affect their prices and concurrently the livelihood of home buyers. The research importance showed that through outlining and ranking of the characteristics quality of houses, one could make better decisions especially purchasing homes that correlate with the prices offered. Significantly, this shows that the research can benefit major stakeholder for landed houses especially with prospecting buyers and also even first time home owners. As purchasing power declines through inflation and appreciation of property prices, homebuyers seen as susceptible in purchasing homes that are exorbitant in prices without the ability to see the qualities that should come with it. Therefore, the researcher provides the aim of this research as to produce ranking characteristics of housing qualities. Objectives outlined were mainly to find out characteristics quality of houses, and ranking the importance of the characteristics quality.

The Analytical Hierarchy Process was used as the methodology of the research to extract and determine a ranking of characteristics quality. The sampling used for this analysis was about 50 respondents from sample population chosen in the District of Klang, Selangor Malaysia. The usage of previous journals and articles as literature review and also Semi-structured interviews were used with expert panels to derive the key features. The usage of a structured questionnaire consisting elements of Saaty's Scale was used to gather data for the research. The main findings of the research have shown that characteristics being described and paired up together had an importance that was significant in a way that affects the quality of life of the respondents. Respondents feel that some characteristics of houses are more important than the other thus this enabled for more study to be conducted to find out especially with the sub-characteristics of houses. The usage of Saaty's Scale and the AHP was implemented to provide uniqueness of the rankings produced by this research. The emphasis for this research to be completed was ultimate to provide an index that enables home buyers to be smarter in their decision to choose and buy prospective houses. This emphasis will become the foundation of future research to be carried on by the researcher. From the results and discussions, a theoretical framework was constructed to facilitate further research.

\footnotetext{
${ }^{*}$ Corresponding author. Tel.:

E-mail address: hilmimasri@gmail.com
}

ISSN: 2398-4287@ 2017. The Authors. Published for AMER ABRA by e-International Publishing House, Ltd., UK. This is an open access article under the CC BYNC-ND license (http://creativecommons.org/licenses/by-nc-nd/4.0/). Peer-review under responsibility of AMER (Association of Malaysian Environment-Behaviour Researchers), ABRA (Association of Behavioural Researchers on Asians) and cE-Bs (Centre for Environment-Behaviour Studies), Faculty of Architecture, Planning \& Surveying, Universiti Teknologi MARA, Malaysia.

DOI: http://dx.doi.org/10.21834/e-bpj.v2i5.702 


\subsection{Literature Review}

\subsection{Characteristics of Housing in Local and Global Context}

In this part, the characteristics of housing can be used in evaluating building types such as terrace houses, semi-detached, detached, stratified units, and even cluster homes. The researcher sees that characteristics can be categorised into physical or non-physical aspects of housing. Karim (2012) states that housing should not be limited to a particular set of house characteristics, but it must be a whole presentation of physicality and also social aspects. This statement can be seen as persuasive towards the characteristics of houses, as it doesn't limit the actual set of items that a house can be measured. Omar, Omar, Othman, \& Yusoff,(2016) also state that concern must not only be on the physical part, but other features such as location and neighbourhood should be addressed. This statement shows that one cannot rely on a particular aspect only, but other important factors also have the ability to give a detailed interpretation of why a specific house is considered important, and what it will contribute towards livelihood qualities.

Housing concepts are aspects of design from the architects and professionals to serve the purpose of fulfilling people's need such as security, aesthetic value, and even investment purposes (Zavei \& Jusan, 2012). The statement gave shows that a housing unit is something that the inhabitants, owners or even renters pride of in managing it. First, we need to see the definition of global housing based on simplest interpretation of its characteristics. The United Nations defines housing as a necessity towards the global human population. It states that because of rapid urbanisation in the world, housing is a key and major component, with the provision of basic infrastructure such as water, sanitation systems, good governance, urban planning, design and physical construction, energy provision and also resource saving (Nations, 2012).

Reaching out further in the global context, as seen in the United Kingdom, housing characteristics follow specialised housing conformity standards in all across the country and were implemented by the local authorities in wholly. Their main emphasis on housing characteristics can be shown as on the size of houses, functionality of houses, the amenities provided, the external environment, and the sustainability of the houses itself (Levitt Bernstein, 2010). The size of housing provided is important as it shows how many households can be fitted inside a single house. Amenities provision is also a part of important characteristics for houses such as lifts for stratified units, nearby playground areas, central heating, hot water, road access and even parking spots. The external environments of areas such as green space and good landscaping also invoke characteristics quality of houses in the UK (Jorgensen, Hitchmough, \& Dunnett, 2007).

In Canada, BC Housing Design Guidelines and Construction Standards are the main standards for characteristics quality in the country. The characteristics mainly focused by the standards are locational, planning, design, construction and functionality (Columbia, 2014). The locational characters also have several sub-topics which include the access to community services, heritage designation, soil conditions and environmental conditions. The sub-topics within locational characteristics are intriguing as it focuses on the concept that houses will provide wellbeing, rather inhabitants providing wellbeing to houses.

In summary, the majority of countries in the world have some form of standard and guidelines for characteristics quality of houses being provided. The argument is that whether these qualities were being provided sufficiently or not, and what are the ways to measure and give weightings to them.

\subsection{Designation and Identification of Building, Locational and Neighbourhood Characteristics of Housing}

Based on the literature and characteristics reviewed by the researcher, it is fair to say that classification of characteristics are important, and although it is confusing, but through proper classification, it can be categorised. The research done by all the researchers outlined are usually tested and can be used as additional characteristics in research especially (Safian, Nawawi, \& Sipan, 2014). Outlined in the table below are the characteristics derived from literature review and to achieve the first objective of research which was to find out characteristics qualities of houses.

Table 1.1 Characteristics of Houses Outlined

\begin{tabular}{|c|c|}
\hline Main Characteristics & Sub-Characteristics \\
\hline Functionality & $\begin{array}{l}\text { Layout Plan } \\
\text { Materials Durability } \\
\text { Number of Rooms } \\
\text { Building Structure } \\
\text { Electrical System }\end{array}$ \\
\hline Presentation & $\begin{array}{l}\text { Number of Storeys } \\
\text { Finishing } \\
\text { Appearance } \\
\text { Flooring Material } \\
\text { Building Built Area } \\
\text { Building Age }\end{array}$ \\
\hline Environment & $\begin{array}{l}\text { Landscaping Works } \\
\text { Drainage } \\
\text { Open Spaces } \\
\text { Green Spaces } \\
\text { External } \\
\text { Specification }\end{array}$ \\
\hline Amenities & $\begin{array}{l}\text { Playing Facilities } \\
\text { Facilities for } \\
\text { Interaction }\end{array}$ \\
\hline
\end{tabular}




\begin{tabular}{ll}
\hline & Gated Housing Area \\
& Parking Provisions \\
& Lighting \\
& Social Practices \\
Community & Conducted \\
& Neighbour \\
& Communications \\
& Fire Safety \\
& Housing \\
& Developments \\
New/old Township \\
Security \\
Cleanliness \\
Noise Level \\
Rubbish Collection \\
Maintenance \\
Provision of Public \\
Transport \\
Nearby Housing \\
Nention & Developments \\
& Nearby Central \\
Business Districts \\
Distance to City \\
Centre \\
Traffic Congestion \\
Nearby Highways \\
Road Networks \\
Fiber Internet \\
Services \\
Driveway \\
Ingress/egress from \\
Residential Area \\
\hline
\end{tabular}

Table 1.1 shows the overall characteristics and sub-characteristics of housing that has been studied from local and global context perspective and will be used as the variables in this research. Based on literature review, it can be concluded that the variables outlined are the basis of measurement to achieve objective number 1 and number 2 respectively.

\subsubsection{The Compilation Framework of Housing Characteristics Qualities}

From the literature review analysis, the framework of the housing characteristics was outlined as above. The researcher has highlighted that they are several issues that can affect house prices mainly house characteristics. It was also shown that complexity of the features and high prices are the major catalysts for the characteristics. By addressing the characteristics through measuring and ranking the characteristics, issues of complexity and high prices can be resolved.

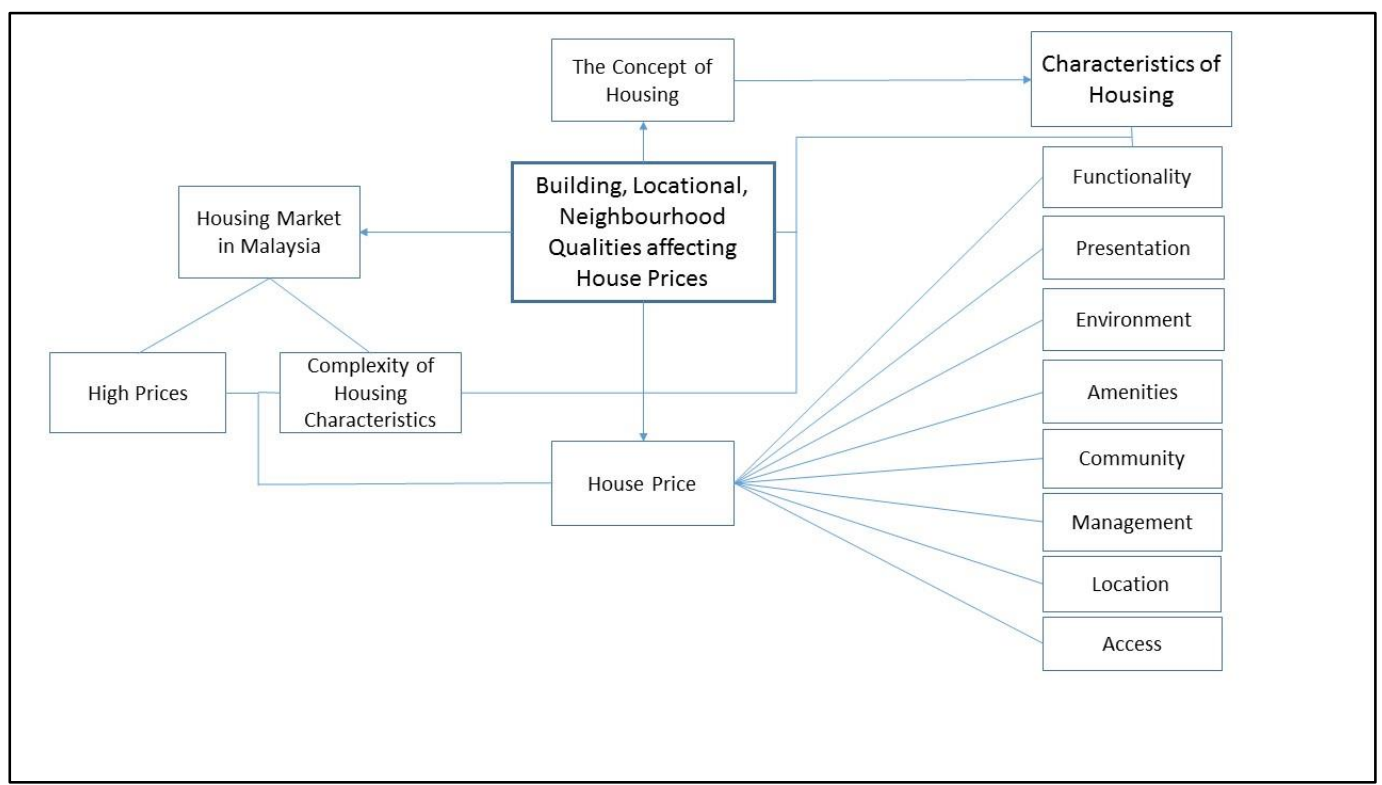

Figure 1: Framework of Housing Characteristics

\subsection{Measurement for Characteristics of Housing}

Based on literature that was gathered and compiled, prevalent issues in previous research as compared to the current research by the researcher on housing qualities showed measurement of qualitative conditions only, rather than showing rigorous measurement 
techniques that were able to be achieved using quantitative measurements. Several studies conducted by Basten \& Koch, (2015), Silva \& Martins,(2016) and Rahadi, Wiryono, Koesrindartoto, \& Syamwil, (2013) showed that measurement towards quality are mostly conducted through the qualitative approach and was finely tailored to fit industry regulations. This statement showed that they are areas overlooked and not addressed properly particularly on methods to measure the quality level of housing. Previous research conducted by other researchers such as Khoiry, Tawil, Hamzah, Ani, \& Sood, (2012), Hillebrand \& Kikuchi, (2015), and Hartley, (2014) showed degree of efforts to identify factors of characteristic house qualities, but their research produced little empirical and theoretical basis in identifying quality level off for each specific characteristics for houses. These studies conducted analysed the factors primarily, and have a minimal amount of measuring and ranking the weightings of the characteristics qualities.

The qualitative approach conducted by the previous researchers have been argued that descriptive research approach does not constitute rigorousness as compared to research that emphasises quantitative approach. Panduro \& Veie, (2013) agrees that qualitative approach can be too descriptive and their interpretations were loose in determining characteristics quality of houses and its weight. Masri, Nawawi, \& Sipan (2016) states that in Malaysia, identifying characteristics qualities of houses using descriptive measurements are not sufficient and rigorous enough.

The discussion above can bring about questionable factors and questionable characteristics whether they are suitable to implement as characteristics. Other researchers such as Safian et al., (2014) believes factors such as building age and characteristics are not only the sole characteristics of houses, but they are many other characteristics. The researcher believes this was a vital indicator for the issue and also part of research gaps to be studied on. Saleh, Hwa, \& Majid, (2016) supports this idea by saying the quality of houses are not determined by their physical characteristics but also influenced by unseen factors surrounding the houses. Van Ommeren \& Van der Vlist, (2016) gives their thought that there were also other various attributes of houses characteristics qualities to be measured, not only on the building age and physical characteristics only. The discussion to include various other characteristics were important as this will help improve people's perception characteristics quality of houses and increase wellbeing quality of lives.

With all due respect to the previous researchers, it was determined that issues of house characteristics quality and their measurement were needed to be addressed thoroughly. The researcher will look into several methods that are deemed suitable to rank the characteristics of housing and has the suitability for adoption in the provision of houses. This statement was supported by Masri et al., (2016) that states adoption to identify housing quality level were mainly descriptive and rigorous quantitative measurement were needed to provide better insight on the issue.

Apart from international and overseas context, the literature review conducted also revealed that research on housing quality in Malaysia is abundant, but most of the research focuses on building characteristics, rather than the wholesome concept of house characteristics qualities and what were the weightages of importance. Several researchers such as Khoiry et al., (2012) and Hashim, (2010) conducts their research on house characteristics qualities through focus groups and expert panels in establishing the characteristics of houses. Amongst their focus groups are house owners, property valuers and also estate agents. All the while, opinions, and views expressed by panel experts and focus groups are credible data, but validation must be conducted by other approaches such as the quantitative approach (Hillebrand \& Kikuchi, 2015).

Through the approaches used by previous researchers, it can be seen that one of the main issue concerns with the methods used to manage, analyse and classify the views and opinions of this expert panels and even focus groups especially before and after an interview. Safian et al., (2014) states that view and opinions of expert panels that are not compiled and managed properly can lead to a misleading interpretation of the data obtained, thus affecting the validity of the data. This was the condition where empirical data needed to be obtained so that methods used before can be validated, confirmed, complemented and enhanced. The second implementation of methods will then be able to demonstrate the suitability of the first collection of knowledge and give significance for research (Adeoye, 2016).

Proper linkages of knowledge obtained through interviews, and the views and opinions were given by the expert panels needed to be complemented and have relation to existing literature and body of knowledge given by other researchers (Safian et al., 2014). As stated by Bakri, Ibrahim, \& Ahmad, (2015) various panel experts with the different background such as an architect will focus more on the design and aesthetic value whereas a property developer was more interested towards development prospect and location of houses. The argument given was good as expert panels also can be exposed to bias according to their expertise and interest. Another statement by Safian \& Nawawi, (2013) supports the argument that without empirical data to back up views and statements given by expert panels, important factors, and characteristics might be overlooked and left out.

Based on the previous discussion, it is vital that this research can characteristics, based on each quality level characteristics qualities of houses. To gain rigorous insight towards this, several methods were needed to be identified and analysed to choose the best method that has the capability of overcoming the stated issues and problems in earlier discussions. The stated matter will then be discussed in detail in the upcoming sub-topic.

\section{Methodology}

\subsection{Qualitative Method}

\subsubsection{Delphi Method}


Delphi method is a research methodology whereby a particular group of people a joined up together for communication process to happen and to establish solution towards overcoming a problem that is considered complex (Safian et al., 2014). The function of the Delphi Method is that the group of people can provide opinions and arguments between them and reach a particular consensus on the best way to overcome a single problem. For this particular research, the researcher has adopted the Delphi Method in getting the best answer for house characteristics based on discussions and agreement from the expert panels chosen.

The expert panels being interviewed using Delphi Method are covered in several rounds, mainly two times by the researcher. This was important as the researcher can gather up their views and opinions thus an indicator list was compiled, and the indicator list was used in the next round of the Delphi Method interview. Delphi Method can gather information and consensus without revealing the identity of expert panels between one another (Quyên, 2014). The two rounds of interview aim to give a review to the opinions and contributions given by all the panels, and the result is expected that all the panels will agree with the set of indicators achieved (Radeljak Kaufmann, 2016).

Based on the method discussed earlier, the researcher was needed to consider this particular method that can be reliable and suitable to determine the ranking of house characteristics. Therefore, the choosing of Delphi Method as the means to gather information especially to support the characteristics of houses derived from the literature review was considered highly significant. The procedure for this can be shown in Table 2 which states to the process of how the Delphi Method was implemented in the research.

\subsection{Quantitative Method Questionnaire Survey}

To achieve the second objective of the research which is to rank the importance of characteristics quality of houses, a quantitative method has to be implied. The weightage of importance for the house characteristics needed to be measured based on the opinions and views of the respondents.

The researcher, therefore, has adopted the Analytic Hierarchy Process to rank the weightage and importance of the house characteristics. The AHP method is systematic measurement method adopted for selecting, ranking and also justifying elements of research, and have the hierarchical structure analysis concept (Abdullah, Jaafar, \& Taib, 2013).

Usage of AHP gave the researcher insight on how to blend the qualitative and quantitative method into a single way to achieve outlined objective which is ranking the importance of house characteristics quality. The AHP gives a ranking of importance thus can answer important questions particularly on the house characteristics (Dinarvandi, Jafari, Mohamadi, \& Hosseini, 2014). The usage of qualitative and quantitative method together will then help structure problems into systematic hierarchy, and the usage of quantitative through questionnaire survey will become the check and balance that determine validity of characteristics based on the opinions of respondents (Safian et al., 2014)

Based on the research done by Tobergte \& Curtis, (2013), three key principles of AHP can be categorised as comparative judgments, synthesis of interest and decomposition. The AHP also provides versatile ability in showing how decision theories are made and to solve particular problems (Erbıyık, Özcan, \& Karaboğa, 2012). Therefore, for this research, the researcher has adopted AHP as the quantitative methodology in achieving the second objective.

From the previous discussion conducted, the AHP Method is not without its limitations. The major limitation expected to be encountered by the researcher is that finding the suitable respondents for the questionnaire, and the willingness of respondents to answer the questionnaire survey. Previous studies conducted by Safian \& Nawawi, (2013), Dinarvandi et al., (2014), Agarwal, Patil, \& Mehar, (2013), and Erbiyık et al., (2012) showed that owners, tenants, and occupants are prospective respondents for the questionnaire survey incorporating AHP. Similar researches conducted by Ho et al., (2005), Pekkonen, Du, Skon, Raatikainen, \& Haverinen-Shaughnessy, (2015), Mulliner, Smallbone, \& Maliene, (2013) and Khoiry et al., (2012) have also shown that the occupants and owners of houses can become the best respondents due to their knowledge and experience living, in particular, residential areas. From this discussion, the researcher has found out that the scope of respondents will be small, particularly in specific residential areas due to the limitation of resources and suitable types of respondents to obtain opinions and views from the questionnaire survey.

Table 2: Research Method and Sampling

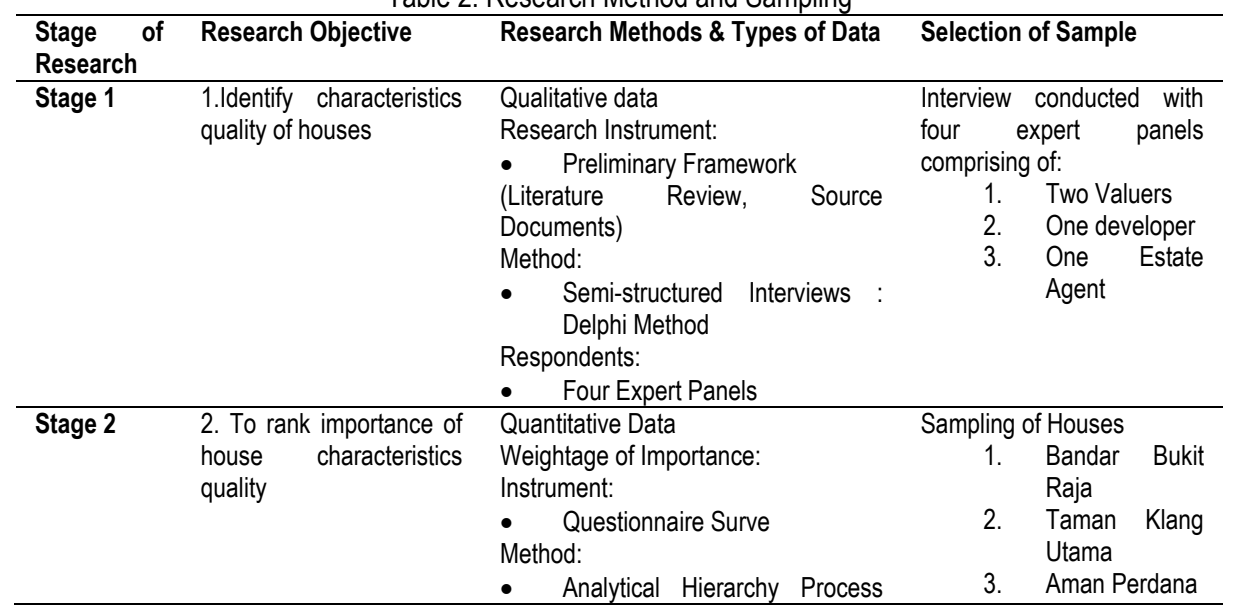




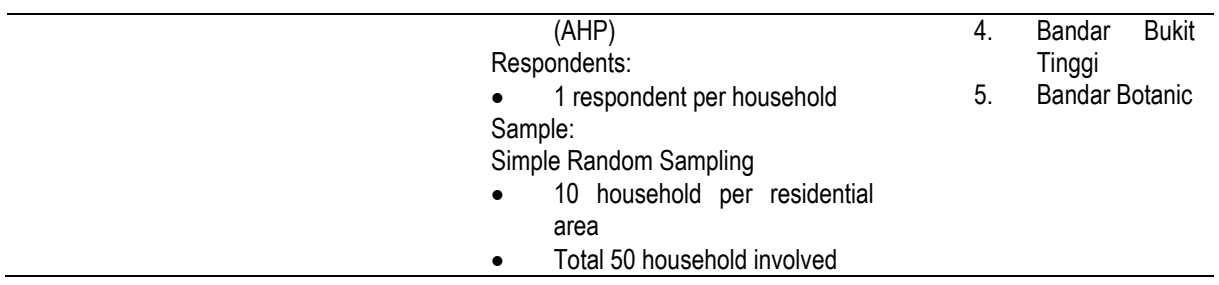

\subsection{Findings}

\subsection{Delphi Method Findings}

In the first stage of the Delphi Method Interview, the researcher has prepared the draft characteristics quality of houses that were derived from the literature review. The draft characteristics quality of houses are the preliminary work that will become the basis for the discussion and items to be improved in the research. Each of the chosen expert panels was given the same draft characteristics quality of houses that they can read and give comments and opinions. The Delphi Method being used in this research was a 2 stage system, which the first stage was to ascertain the characteristics quality of houses by the expert panels, and the second stage is the researcher makes amendments based on the comments and discussions. The second draft of characteristics quality of houses was then compiled and brought to the expert panels for validation.

The first meeting conducted with the expert panels were done with a set a semi-systematic set of questions. The experts were free to answer all the questions given and they are also given freedom to give their answer and opinions not following prescribed questions. This was done to get the maximum amount of information disclosure from the panel that is genuine and not unbiased towards interview questions. The chosen expert panel in this research consists of two valuers, one estate agent and one developer, all considered to be the expert in their field and particularly in the provision of houses.

The first meeting that was conducted with the four expert panels happens at a different time and location. This was done to facilitate with their busy schedule in entertaining the researcher. Nevertheless, this does not affect the outcome and findings gained from conducting the interview. In the table below is highlighted the relevant findings that were obtained from the first and second stage of the Delphi Method Interviews. The findings highlighted will then be further discussed in the next sub-topic.

Table 3: Delphi Method Findings

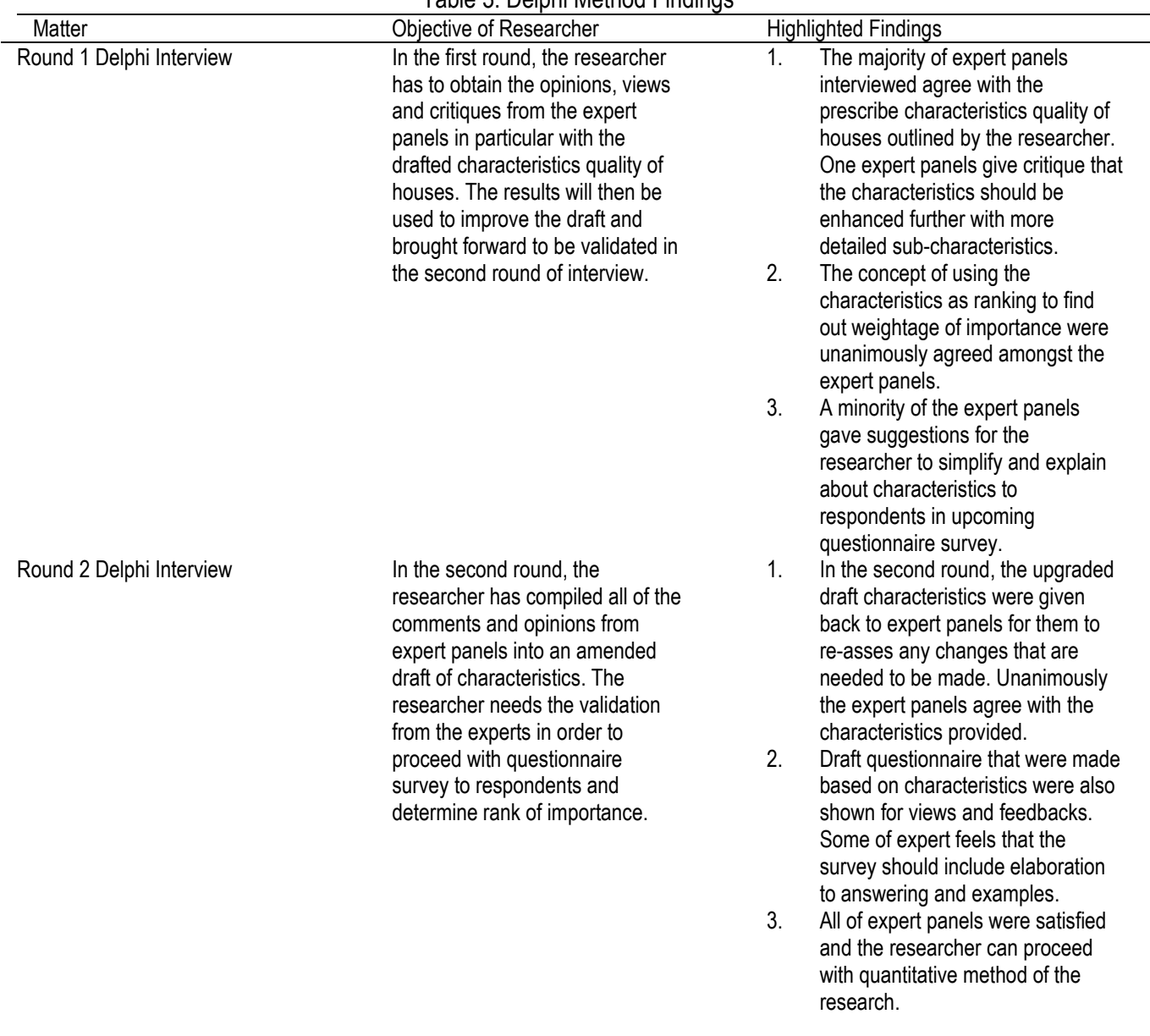




\subsection{AHP Findings}

The AHP analysis was conducted by gathering all the respondent's perception based on the questionnaire survey distributed to them earlier. The data gathered were inputted in the SPSS 22 to derive the frequency analysis of the survey. This was vital as to provide the number of the median that can be used in the weightage of AHP. The median value can be as more accurate to use as value as it provides most accurate reflection on respondents perception (Safian et al., 2014). After the median for each of the variable was obtained, then the usage of AHP can be utilised. The researcher has utilised the AHP template provided by (Goepel, 2010) that has facilitate ease into the ranking of importance characteristics quality of houses. This, in turn, has provided the ranking based on some criteria from 1 until 8 . Number one will be the most important and the number eight to be least important.

Figure 3 has shown the finalised findings derived from the AHP analysis, and the template has provided the ranking of importance for characteristics quality of houses. It is notable to highlight the findings that the characteristic of location yields the highest rank of number 1, as opposed to the lowest rank of functionality and presentation respectively. The analysis and discussion of the findings here will be discussed in more detail in the next sub-topic.

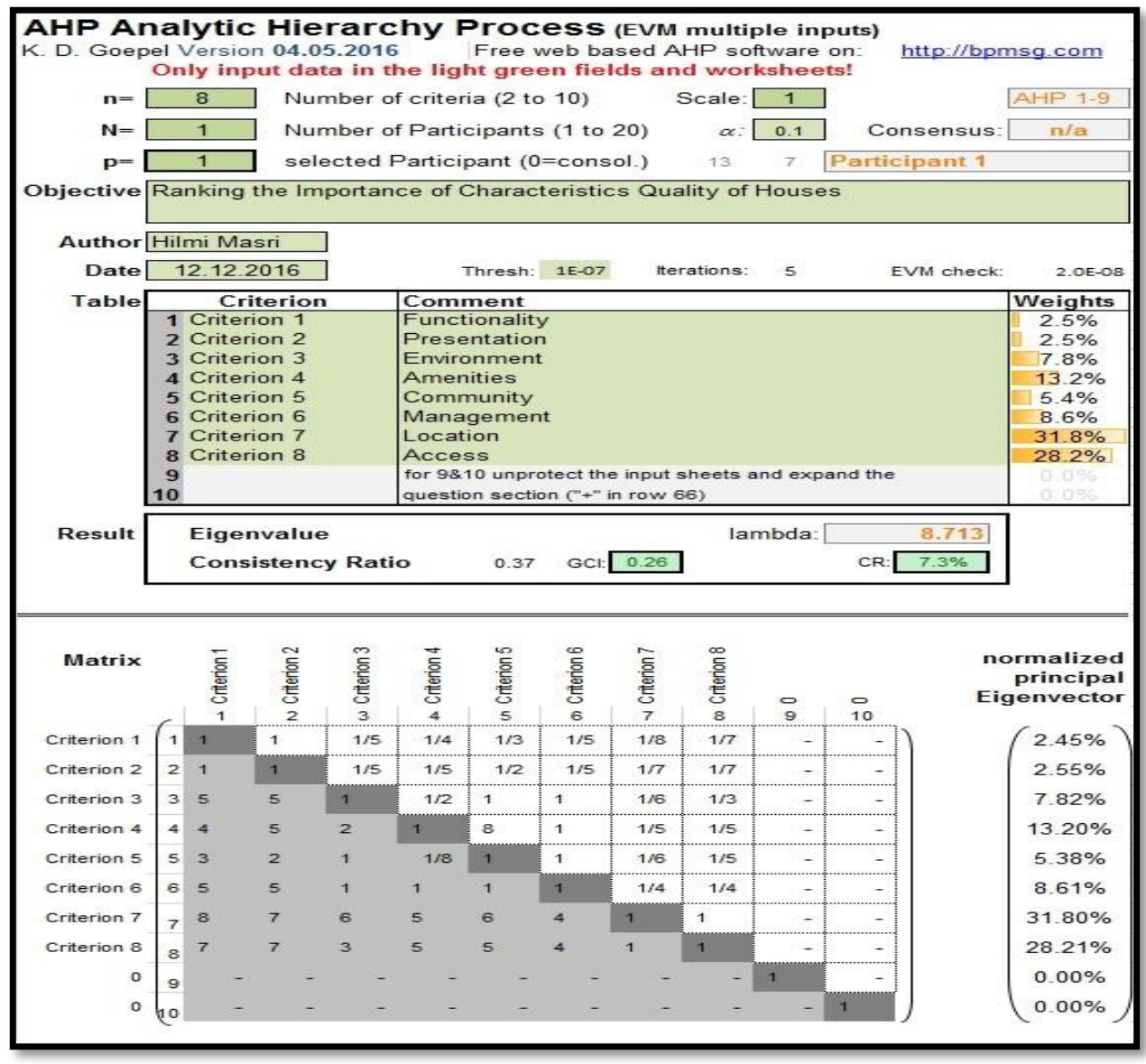

Figure 3: Findings through AHP Analysis to Rank Importance Characteristics Quality of Houses

\section{Discussion and Analysis}

\subsection{Delphi Method}

From the highlighted findings in Table 3, the researcher has found out that the characteristics obtained from the literature review have sufficiently pleased the expert panels regarding their opinion and views. Based on their knowledge and experience, the number of characteristics described which are functionality, presentation, environment, amenities, community, management, location and access was deemed suffice to show the ranking of their importance. The majority of the expert panels can agree on the characteristics except for one panel who feels that the characteristics should enhance and focus more on the sub-characteristics. This issue was explained by the researcher that the sub-characteristics would be enhanced further in the next future research that will show more rigorous measurement and rank involved. For the purpose of disseminating findings and analysis for this paper, it is deemed sufficient as the researcher has limitations which are time constraint and the resources to provide more in-depth measurements and ranking. After further discussion, the panel who disagrees in the first place gives his view that this is sufficient and his decision was also changed to agree with the rest of the panels. 
After all the expert panels unanimously agree in the first round of the Delphi Interview, the researcher incorporates the views and opinions gathered from them to revise the first draft of the characteristics quality. This includes the explanation of characteristics and also the sub-characteristics quality of house in the drafted questionnaire survey. The explanation of each characteristic was important to make sure that the respondents truly understand the survey filled out thus reducing the number of invalid answers given. The suggestion from expert panels to give a proper example on how to fill questionnaire was also taken up as the AHP questionnaire survey can be quite overwhelming to respondents, especially from demographics with low understanding of academic terms and jargons.

In the second round of the Delphi interview, the researcher brought the amend characteristics that have been incorporated into the questionnaire survey for the purpose of quantitative. The amendments were based on their previous views and opinions, and they have the ability to reassess the characteristics and reevaluate their previous decisions. Nevertheless, unanimous agreement was achieved between them and the expert panels feel that the researcher can carry out doing the questionnaire survey based on the agreed characteristics.

\subsection{AHP Analysis}

The findings from figure 3 of the previous sub-topic were arguably one the most important aspects of the research. By using the median derived from the frequency analysis of respondent's views, the researcher has generated significant findings on characteristics which were deemed most important and also the least important. From the figure, it can be seen that the most important characteristic chosen by the respondents was the location characteristics with $31.80 \%$. This high number of percentage supersede the second most important characteristics which generated $28.21 \%$ importance. The location aspect showed that respondents prefer houses that have the best features of location such as public transport, nearby housing developments, central business districts, distance to the city was and the amount of traffic congestion. In the theories provided in the previous literature review, location aspect can be a major catalyst for a homebuyer to achieve higher living qualities. As human are social creatures, they prefer to live nearby housing areas that have all the provision to ease their lives. Work opportunities are abundant in central business districts, and traffic congestion is something that respondents feel they need to avoid. As such, the location aspect will generate the highest weightage due to its importance and become a key factor in making the decision to purchase homes.

The second highest importance was access with $28.21 \%$ result. This finding was the second highest just behind the location aspect. Access relates to road networks, highways, internet services, driveway and also ingress-egress from a residential area. The concept of modern living nowadays has seen more and more people living in urban areas. Thus this access factor has become a vital part of their lives. People want easier access, access to information, ability to move around from point $A$ to $B$, and generally ability to traverse easily in and out of their homes. The concept of living in rural areas deemed less access can be achieved by homeowners thus reducing their perception of the quality of living.

The third highest importance can be seen as amenities with $13.2 \%$ result. The provision of amenities has long been speculated as an integral part of housing but this measurement has shown the result and proved the condition. Amenities such as playing facilities, facilities for interaction, gated housing area, parking and also lighting in their area are deemed important. This can be summarised as people perceives amenities to be part of higher living quality thus ranking them important. Home with better amenities equates to higher weightage in providing them with the services, safety, and enjoyment of living.

The fourth highest findings were the management aspect with $8.61 \%$. The analysis on this was that people nowadays wanted to live in houses that are well managed, as they have forked out a considerable amount of money to purchase them. They expect that security, cleanliness, noise level management, rubbish collection and maintenance were all provided. The way cities governed now demands them to pay assessment rate. Therefore, they want the best services with the money paid. A city with a weak local council management may equate to less desirable homes for respondents.

The next ranking considered the environment with $7.80 \%$ weightage. The environment relates to the external factors of the houses such as landscaping, drainage, open spaces and green spaces. Respondents might feel the characteristics to be less important as this was something that has already been established and they have no control over it. Respondents might also feel that this is not their responsibility thus ranking it lower. The low perception also points towards a lack of concern and apathy towards the environment.

The three lowest ranking which was the community at $5.40 \%$, presentation and functionality at $2.50 \%$ each respectively. These three lowest ranking can be grouped together as the least desirable characteristics by respondents thus having the lowest weightage. For the community, the aspect of social practices, neighbour communication, fire safety, other housing developments and township were not well received by respondents. In this polarising age of technology, people are getting more separated with others even though they live in the same neighbourhood or residential areas. Provision of things necessary for individual interest is given more focus in this aspect. The functionality and presentation aspect were the lowest weightages by the respondents. The item such as layout plan, materials durability, finishing, flooring material and such does not concern them. These can be related to low exposure in maintenance and the general sense of apathy in taking care of their homes due to other important items to be focused on such as living expenses, mortgages and such. The implication beyond this further research is that the public in Malaysia needed to be educated on this importance, for them to improve their living quality in the country.

From the analysis of the findings, nevertheless, rigorous measurement can be achieved by incorporating Qualitative and Quantitative Method together to bring out the best results. The results from analysis can thus be used as the basis for recommendations and further research to be conducted especially on the sub-characteristics. 


\section{Conclusion and Recommendations}

The research conducted aims to produce the ranking characteristics of housing qualities through its two objectives to be achieved which are finding out the characteristics quality of houses and ranking the importance of the characteristics quality. The overall evaluation by the researcher found out that the first and second objectives of the research have been achieved primarily through the methodology of literature review, Delphi Method, and Analytical Hierarchy Process. The contributions expected in this research is that the weightage of each characteristic will serve as an important catalyst in determining attributes of good quality houses. The research conducted was based on a small number of respondent thus enabling this research to be a pilot study for upcoming research to be undertaken.

The researcher recommends that to improve the situation. First a higher number of sampling needs to be conducted to ensure that the measurement truly reflects the population in the targeted scope of the research area. A higher sampling can ensure higher accuracy and reduce the number of invalid results. But these depend on limitations such as time constraint, population size and also resources needed.

Secondly, the researcher recommends that the necessary authorities adopt the measurement and ranking of weightages and to incorporate them when giving out development approvals for developers and even projects undertaken by themselves. Another suggestion is that the public needs to be educated on the wholesomeness of a house, especially on the management and maintenance aspects as this relate with their daily livelihood, and not to focus only on the external aspects of their neighbourhood and also provisions that only will benefit individuals.

The identification of new directions of research can be seen to replicate the methodology and measurement of research into other areas of study in Malaysia such as Kuantan, Ipoh, Johor Bahru and Penang. The idea for this is that the research can serve as a benchmark for characteristics quality of houses and thus providing better views in making decision to purchase them. The research must also be expanded to incorporate the relationship of these characteristics qualities with the provision of house prices being offered. The theoretical framework derived from the current research as shown in Figure 4 will serve as an expansion of the research in the future.

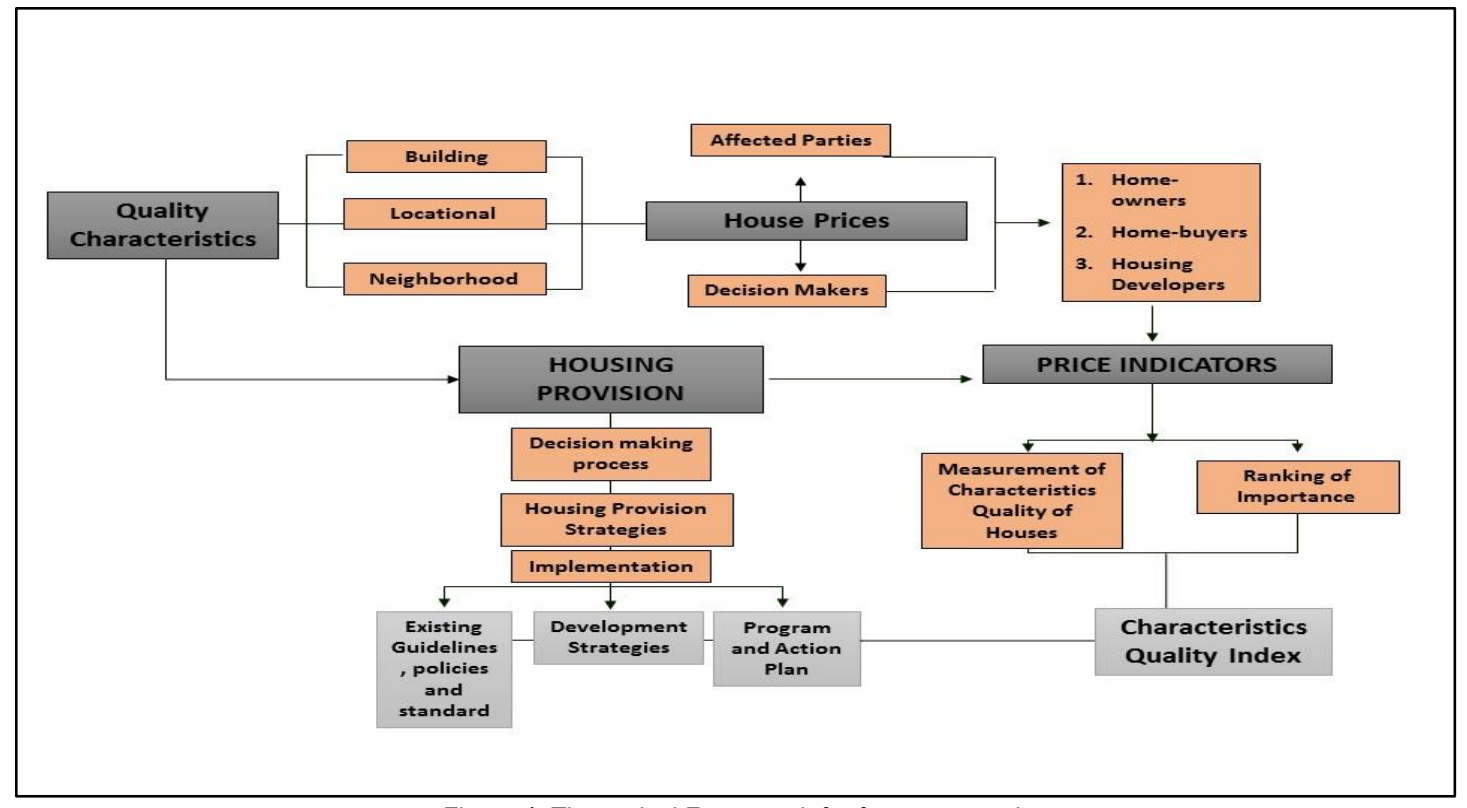

Figure 4: Theoretical Framework for future research

\section{Acknowledgements}

The researcher acknowledges the other authors in this paper for giving tremendous support in completing this paper. Many thanks also to my dearest wife and daughter for your understanding. The researcher would also like to thank MyBrain15-KPT in giving the financial support in completing this paper.

\section{References}

Abdullah, L., Jaafar, S., \& Taib, I. (2013). Ranking of Human Capital Indicators Using Analytic Hierarchy Process. Procedia - Social and Behavioral Sciences, 107(2007), 22-28. http://doi.org/10.1016/j.sbspro.2013.12.394

Adeoye, D. O. (2016). Challenges of Urban Housing Quality: Insights and Experiences of Akure, Nigeria. Procedia - Social and Behavioral Sciences, 216(October 2015), 260-268. http://doi.org/10.1016/j.sbspro.2015.12.036 
Agarwal, P. K., Patil, P. K., \& Mehar, R. (2013). A Methodology for Ranking Road Safety Hazardous Locations Using Analytical Hierarchy Process. Procedia - Social and Behavioral Sciences, 104, 1030-1037. http://doi.org/10.1016/j.sbspro.2013.11.198

Bakri, A. F., Ibrahim, N., \& Ahmad, S. S. (2015). Valuing Built Cultural Heritage in a Malaysian Urban Context. Procedia - Social and Behavioral Sciences, 170, 381389. http://doi.org/10.1016/j.sbspro.2015.01.048

Basten, C., \& Koch, C. (2015). The causal effect of house prices on mortgage demand and mortgage supply : Evidence from Switzerland R. Journal of Housing Economics, 30, 1-22. http://doi.org/10.1016/j.jhe.2015.07.001

Columbia, B. (2014). Guidelines. BC Housing.

Dinarvandi, M., Jafari, H., Mohamadi, M., \& Hosseini, A. (2014). Improving the Quality of Service to the Urban Environment for Sustainable Development. Procedia Social and Behavioral Sciences, 120, 487-495. http://doi.org/10.1016/j.sbspro.2014.02.128

Erbıyık, H., Özcan, S., \& Karaboğa, K. (2012). Retail Store Location Selection Problem with Multiple Analytical Hierarchy Process of Decision Making an Application in Turkey. Procedia - Social and Behavioral Sciences, 58, 1405-1414. http://doi.org/10.1016/j.sbspro.2012.09.1125

Goepel, A. K. D. (2010). BPMSG AHP Excel Template with multiple Inputs, 1-6.

Hartley, D. (2014). The effect of foreclosures on nearby housing prices: Supply or dis-amenity? Regional Science and Urban Economics, 49 , $108-117$. http://doi.org/10.1016/j.regsciurbeco.2014.09.001

Hashim, Z. A. (2010). House Price and Affordability in Housing in Malaysia [ Harga Rumah dan Tahap Mampu Milik Rumah di Malaysia]. Akademika, 78, 37-46. Retrieved from http://pkukmweb.ukm.my/ penerbit/akademika/jademik.html

Hillebrand, M., \& Kikuchi, T. (2015). A mechanism for booms and busts in housing prices. Journal of Economic Dynamics and Control, 51, $204-217$. http://doi.org/10.1016/j.jedc.2014.09.033

Ho, D., Chau, K., Yau, Y., Cheung, A., \& Wong, S. (2005). Comparative study of building performance assessment schemes in Hong Kong. The Hong Kong Surveyor, 16(June), 47-58. Retrieved from /citations?view_op=view_citation\&continue=/scholar?hl=en\&start=320\&as_sdt=0,5\&scilib=1\&citilm=1\&citation_for_view=n2mStcoAAAAJ:SP6oXDckpogC\&hl=en\&oi=p

Jorgensen, A., Hitchmough, J., \& Dunnett, N. (2007). Woodland as a setting for housing-appreciation and fear and the contribution to residential satisfaction and place identity in Warrington New Town, UK. Landscape and Urban Planning, 79(3-4), 273-287. http://doi.org/10.1016/j.landurbplan.2006.02.015

Karim, H. A. (2012). Low Cost Housing Environment: Compromising Quality of Life? Procedia - Social and Behavioral Sciences, 35(December 2011), 44-53. http://doi.org/10.1016/j.sbspro.2012.02.061

Khoiry, M. A., Tawil, N. M., Hamzah, N., Ani, A. I. C., \& Sood, S. (2012). Critical Factors Affecting Double Storey Terrace Houses Prices in Bandar Baru Bangi. Procedia - Social and Behavioral Sciences, 60, 562-566. http://doi.org/10.1016/j.sbspro.2012.09.423

Levitt Bernstein. (2010). A new approach to housing standards. Retrieved http://www.housinglin.org.uk/_library/Resources/Housing/Support_materials/Other_reports_and_guidance/A4_Full_proposal_rev5.pdf

Masri, M. H. b M. @, Nawawi, A. H. b, \& Sipan, I. b. (2016). Review of Building, Locational, Neighbourhood Qualities Affecting House Prices in Malaysia. Procedia Social and Behavioral Sciences, 234, 452-460. http://doi.org/10.1016/j.sbspro.2016.10.263

Mulliner, E., Smallbone, K., \& Maliene, V. (2013). An assessment of sustainable housing affordability using a multiple criteria decision making method. Omega, 41(2), 270-279. http://doi.org/10.1016/j.omega.2012.05.002

Nations, U. (2012). No Title. Retrieved from http://unhabitat.org/urban-themes/housing-slum-upgrading/

Omar, D., Omar, K. A., Othman, S., \& Yusoff, Z. M. (2016). Youth Participation in Urban Neighbourhood Community. Procedia - Social and Behavioral Sciences, 234, 309-316. http://doi.org/10.1016/j.sbspro.2016.10.247

Panduro, T. E., \& Veie, K. L. (2013). Classification and valuation of urban green spaces-A hedonic house price valuation. Landscape and Urban Planning, 120, 119128. http://doi.org/10.1016/j.landurbplan.2013.08.009

Pekkonen, M., Du, L., Skon, J. P., Raatikainen, M., \& Haverinen-Shaughnessy, U. (2015). The influence of tenure status on housing satisfaction and indoor environmental quality in Finnish apartment buildings. Building and Environment, 89, 134-140. http://doi.org/10.1016/j.buildenv.2015.02.003

Quyên, Đ. T. N. (2014). Developing University Governance Indicators and their Weighting System Using a Modified Delphi Method. Procedia - Social and Behavioral Sciences, 141, 828-833. http://doi.org/10.1016/j.sbspro.2014.05.144

Radeljak Kaufmann, P. (2016). Integrating factor analysis and the Delphi method in scenario development: A case study of Dalmatia, Croatia. Applied Geography, 71, 56-68. http://doi.org/10.1016/j.apgeog.2016.04.007

Rahadi, R. A., Wiryono, S. K., Koesrindartoto, D. P., \& Syamwil, I. B. (2013). Attributes Influencing Housing Product Value and Price in Jakarta Metropolitan Region. Procedia - Social and Behavioral Sciences, 101, 368-378. http://doi.org/10.1016/j.sbspro.2013.07.211

Safian, E., \& Nawawi, A. H. (2013). Characteristics of Purpose-built Office. Procedia - Social and Behavioral Sciences, 101 , 575-584. http://doi.org/10.1016/j.sbspro.2013.07.230

Safian, E., Nawawi, A. H., \& Sipan, I. (2014). Building and Locational Characteristic's Quality of Purpose-Built Office and their Relationship with Rentals. MPRA, 64908(61160). 
Saleh, A. F. A., Hwa, T. K., \& Majid, R. (2016). Housing Mismatch Model in Suburban Areas. Procedia - Social and Behavioral Sciences, 234, 442-451. http://doi.org/10.1016/j.sbspro.2016.10.262

Silva, A. C., \& Martins, P. (2016). The role of perceived housing quality and perceived choice to recovery : An ecological perspective on a housing fi rst program in Lisbon, 47, 44-52. http://doi.org/10.1016/j.jenvp.2016.05.004

Tobergte, D. R., \& Curtis, S. (2013). How you can use AHP to make key business decisions. Journal of Chemical Information and Modeling, 53(9), 1689-1699. http://doi.org/10.1017/CBO9781107415324.004

Van Ommeren, J. N., \& Van der Vlist, A. J. (2016). Households' willingness to pay for public housing. Journal of Urban Economics. http://doi.org/10.1016/j.jue.2015.11.007

Zavei, S. J. A. P., \& Jusan, M. M. (2012). Exploring Housing Attributes Selection based on Maslow's Hierarchy of Needs. Procedia - Social and Behavioral Sciences, 42(July 2010), 311-319. http://doi.org/10.1016/j.sbspro.2012.04.195 